\title{
Contribution of molecular analyses to the estimation of the risk of congenital myotonic dystrophy
}

\author{
A M Cobo, J J Poza, L Martorell, A López de Munain, J I Emparanza, M Baiget
}

\begin{abstract}
A molecular analysis of the maternal and child CTG repeat size and intergenerational amplification was performed in order to estimate the risk of having a child with congenital myotonic dystrophy (CMD). In a study of 124 affected mother-child pairs (42 mother-CMD and 82 mother-non-CMD) the mean maternal CTG allele in CMD cases was three times higher (700 repeats) than in nonCMD cases (236 repeats). When the maternal allele was in the 50-300 repeats range, $90 \%$ of children were non-CMD. In contrast, when the maternal allele was greater than 300 repeats, $59 \%$ inherited the congenital form. Furthermore, the risk of having a CMD child is also related to the intergenerational amplification, which was significantly greater in the motherCMD pairs than in the mother-non-CMD pairs. Although the risk of giving birth to a CMD child always exists for affected mothers, our data show that such a risk is considerably higher if the maternal allele is greater than $\mathbf{3 0 0}$ repeats.
\end{abstract}

( $($ Med Genet 1995;32:105-108)

Myotonic dystrophy (DM) is the most common form of adult muscular dystrophy, with an estimated incidence of 1 in 8000 in most populations. ${ }^{1} \mathrm{DM}$ is a multisystemic autosomal dominant disorder with highly variable expression including myotonia, progressive muscle weakness, and cataracts. The mutation underlying DM has been characterised as an expanded CTG trinucleotide repeat sequence in the $3^{\prime}$ untranslated region of a protein kinase gene on chromosome 19q13.2-13.3 whose size correlates with the clinical severity of the disorder. $^{2-7}$ The phenomenon of anticipation within families, with decreasing age of onset and increasing severity of symptoms in succeeding generations, has been documented. ${ }^{8-10}$ Furthermore, the observed intergenerational amplification of CTG repeat in the majority of the families has provided a biological basis for

DM can also occur as a severe neonatal form almost exclusively transmitted by carrier mothers. The major clinical features of congenital myotonic dystrophy (CMD) are severe neonatal hypotonia, respiratory distress, facial weakness, mental retardation, and high mor-

tality. Hydramnios, reduced fetal movements during pregnancy, and talipes are also frequent findings. ${ }^{15}$ Previous studies have estimated the risk of having a congenitally affected child to be about 10 to $40 \% .{ }^{16} \mathrm{~A}$ correlation between the maternal size of the CTG repeat and the frequency of CMD has been suggested. ${ }^{12} \mathrm{We}$ present a quantitative study of the risk for carrier mothers of having a CMD child based on their repeat size.

\section{Patients and methods}

DIAGNOSIS OF DM

Clinical diagnosis of DM was made according to the criteria of Harper ${ }^{1}$ and the definition of the Working Group on the molecular defect in DM. ${ }^{17}$ The diagnostic criteria for CMD were hypotonia at birth, neonatal respiratory distress, mental retardation, facial weakness, and diagnosis of DM in the infant's mother or other relative.

\section{DNA ANALYSES}

Genomic DNA $(5 \mu \mathrm{g})$ was digested with EcoRI and the fragments separated on a $0.6 \%$ agarose gel. Southern transfer was performed by alkali blotting onto Hybond N (Amersham) and hybridised to ${ }^{32} \mathrm{P}$ labelled cDNA2 $5^{4}$ or pGP2. $6^{2}$ for 16 hours at $65^{\circ} \mathrm{C}$ according to standard procedures. The filters were washed to a stringency of $0.1 \times \mathrm{SSC}, 0.1 \% \mathrm{SDS}$, and autoradiography was for four to eight days at $-80^{\circ} \mathrm{C}$. PCR analysis for the detection of minimal CTG repeat expansions was performed as follows: reactions $(50 \mu \mathrm{l})$ were set up using standard PCR conditions $(50 \mathrm{mmol} / 1 \mathrm{KCl}$, $1.5 \mathrm{mmol} / 1 \mathrm{MgCl}_{2}, 10 \mathrm{mmol} / 1$ Tris$-\mathrm{HCl}, \mathrm{pH}$ $8 \cdot 3,200 \mathrm{mmol} / 1 \mathrm{dNTPs}, 1 \mu \mathrm{mol} / 1$ each primer, 700 ng DNA, and 1 U Taq DNA polymerase. Cycling conditions were as follows: $1 \times($ three minutes, $94^{\circ} \mathrm{C}$ ), $30 \times$ (one minute 30 seconds, $94^{\circ} \mathrm{C}$; one minute, $67^{\circ} \mathrm{C}$; two minutes, $72^{\circ} \mathrm{C}$ ), $1 \times$ (seven minutes, $72^{\circ} \mathrm{C}$ ), $4^{\circ} \mathrm{C}$ soak. Samples were then loaded on $3.5 \%$ NUSIEVE gels and electrophoresis was performed at $120 \mathrm{~V}$ for two hours. The primers used, 101 and 102, have been previously described. ${ }^{3}$

CTG expansion was examined in 124 mother-child pairs affected with DM, including 42 mother-CMD and 82 mother-DM children. To compare the expansion sizes between CMD and non-CMD cases, the size of the CTG allele was also determined in a random sample of 346 typical DM (non-CMD) patients. The CTG repeat number was calculated from the expansion in kilobases estimated from autothis phenomenon. ${ }^{11-14}$

Epidemiology

Ntra Sra de Aránzazu,

San Sebastián 20080

Pau, Barcelona,

M Baiget
} 


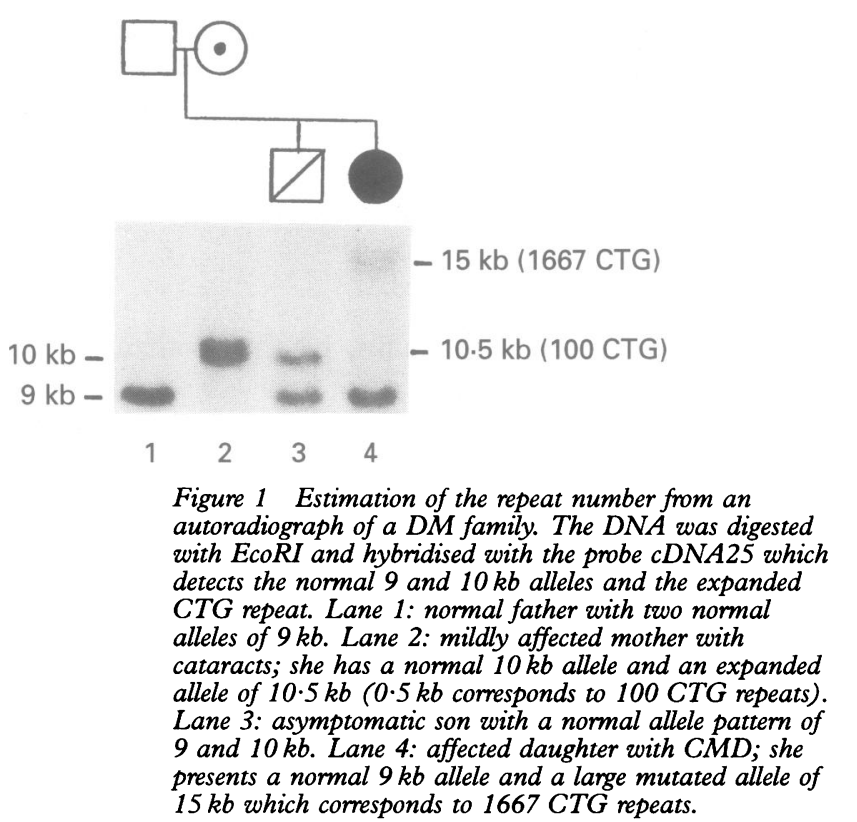

Congenital cases
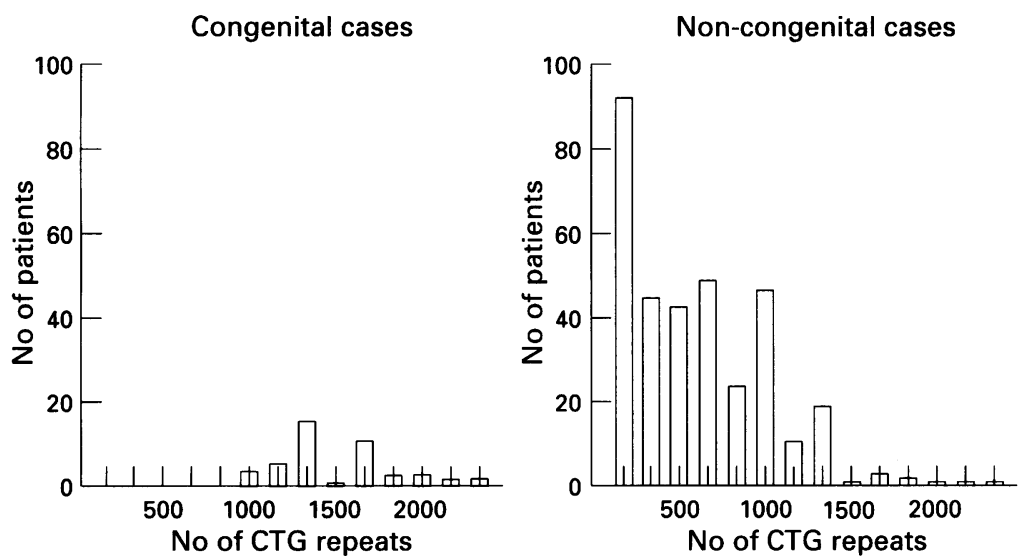

Figure 2 Distribution of the CTG allele size according to the clinical status.

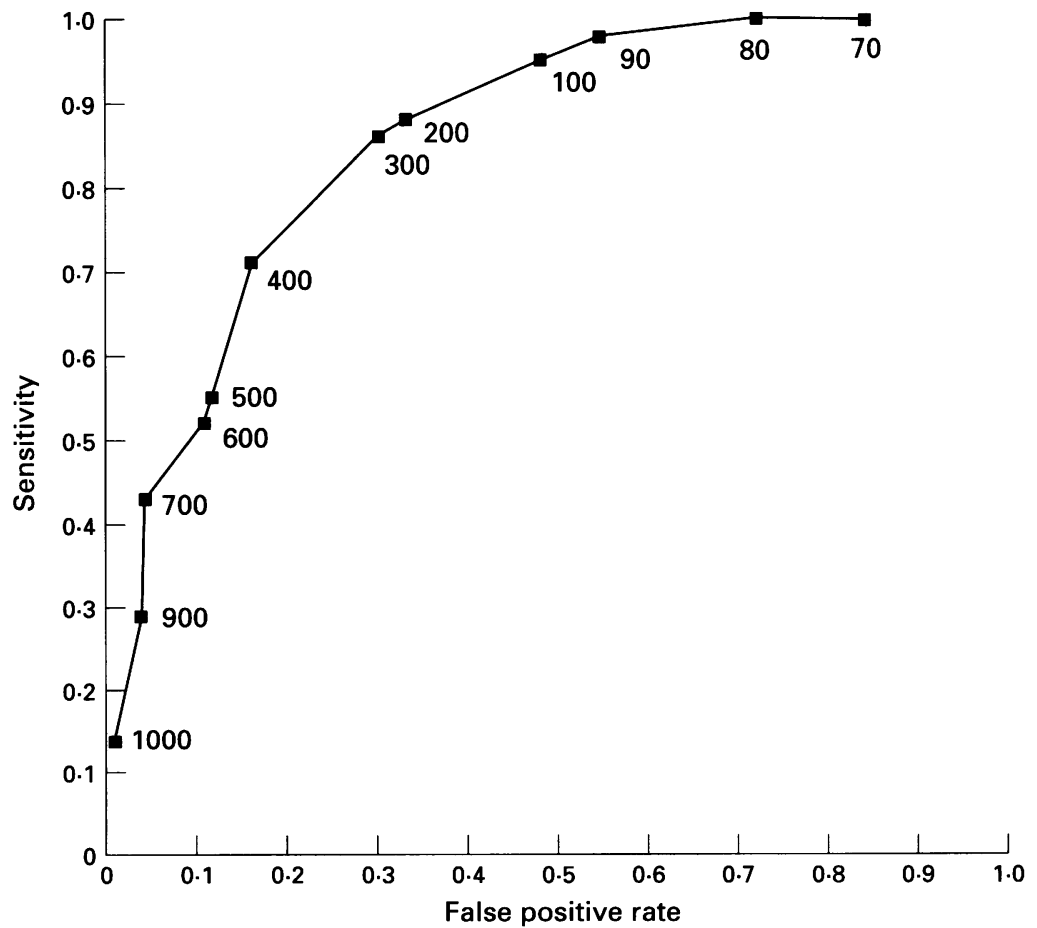

Area under $\mathrm{ROC}=0.838$

Figure 3 ROC curve for the estimation of the cut off point.
Table 1 Mean maternal allele size in CMD and nonCMD cases

\begin{tabular}{lll}
\hline & $\begin{array}{l}\text { Mother/child } \\
\text { pairs }\end{array}$ & $\begin{array}{l}\text { No of maternal } \\
\text { CTG repeats }\end{array}$ \\
\hline & & 700 \\
CMD & 42 & $(80-2333)$ \\
Non-CMD & 82 & 236 \\
& & $(65-1167)$
\end{tabular}

Student's $t$ test $\mathrm{p}<0.001$.

Table 2 Distribution of the children according to the size of maternal allele, for a cut off point of 300 repeats

\begin{tabular}{llll}
$\begin{array}{l}\text { Maternal } \\
\text { allele }\end{array}$ & $\begin{array}{l}\text { No of CMD } \\
\text { cases }\end{array}$ & $\begin{array}{l}\text { No of non- } \\
\text { CMD cases }\end{array}$ & Total \\
\hline >300 CTG & 36 & 25 & 61 \\
<300 CTG & 6 & 57 & 63 \\
Total & 42 & 82 & 124 \\
\hline
\end{tabular}

radiographs (fig 1 ) where $1 \mathrm{~kb}$ corresponds to 333 repeats. The repeat number in smear bands was estimated from the lower limit of the smear.

STATISTICAL ANALYSIS

A comparison between the size of the maternal allele and the intergenerational amplification in CMD cases and in non-CMD cases was performed with Student's $t$ test. The best cut off point regarding sensitivity and specificity was defined graphically by means of a Receiver Operating Characteristics (ROC) curve. The relative risk of having a CMD child was estimated calculating the odds ratio (OR) from a $2 \times 2$ table.

\section{Results}

In the group of $42 \mathrm{CMD}$ patients, the average CTG allele size was 1496 (SD 348) repeats, with sizes ranging from 1000 to 2300 repeats. In a random sample of non-CMD patients $(\mathrm{n}=$ 346), the average allele size was 581 (SD 444), with a lower limit of 50 repeats and the largest repeat size being 2300 repeats (fig 2). An overlap exists between both groups; $21 \%(9 / 42)$ of CMD children showed relatively modest CTG alleles of between 1000 and 1200 repeats, while $9 \%(31 / 346)$ of the non-CMD patients had repeat lengths in the upper range of CMD patients. Hence, the large repeat number observed in the CMD group is not a sufficient condition for the development of CMD.

Our study showed different sized alleles in the mothers of CMD $(n=42)$ and non-CMD children $(n=82)$. The mean maternal CTG repeat size in the former group was significantly higher ( $\mathrm{p}<0.001$, Student's $t$ test) than in the latter (table 1).

A cut off point of 300 CTG repeats determined by an ROC curve was chosen to predict the occurrence of CMD cases with a maximum specificity and sensitivity. At the point of 300 CTG repeats, the sensitivity (36 CMD cases for maternal repeat size greater than 300 repeats $/ 42$ total CMD cases) was $86 \%$ and the specificity ( 57 non-CMD cases for maternal repeat size less than 300 repeats/ 82 total non-CMD cases) was $70 \%$ (table 2 , fig 3). If a lower cut off point of 100 repeats is considered, the sensitivity increases to $95 \%$ but 
Table 3 Intergenerational behaviour of the CTG repeat in the mother-child pairs

\begin{tabular}{|c|c|c|c|c|}
\hline & \multicolumn{2}{|c|}{ CTG increase } & \multirow{2}{*}{$\frac{\text { No change in } C T G}{\text { No }}$} & \multirow{2}{*}{$\begin{array}{l}\text { CTG decrease } \\
\text { No }\end{array}$} \\
\hline & No & Mean & & \\
\hline Mother-CMD & $\begin{array}{l}40 / 42 \\
(96 \%)\end{array}$ & 861 & $\begin{array}{l}1 / 42 \\
(2 \%)\end{array}$ & $\begin{array}{l}1 / 42 \\
(2 \%)\end{array}$ \\
\hline Mother-non-CMD & $\begin{array}{l}71 / 82 \\
(87 \%)\end{array}$ & 555 & $\begin{array}{l}10 / 82 \\
(12 \%)\end{array}$ & $\begin{array}{l}1 / 82 \\
(1 \%)\end{array}$ \\
\hline
\end{tabular}

Student's $t$ test $\mathrm{p}<0.001$

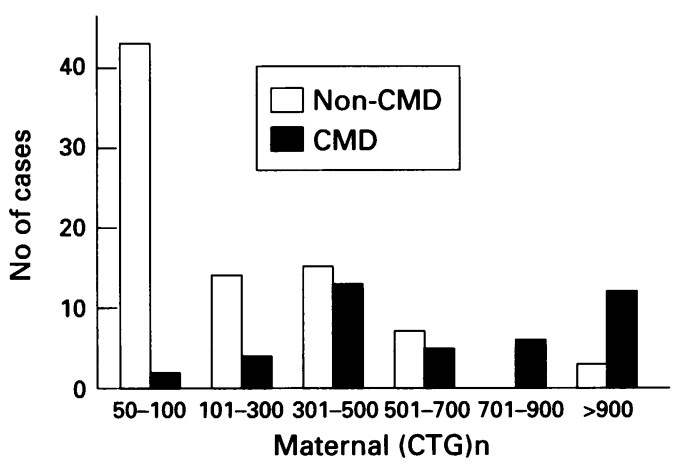

Figure 4 Comparison of CTG repeat lengths between mothers of $C M D$ and non-CMD patients.

the specificity is only $48 \%$. In contrast, for a cut off point of 500 repeats, the sensitivity decreases greatly to $55 \%$ despite a high specificity of $96 \%$.

If the number of CMD and non-CMD cases in relation to the maternal allele are plotted, we observe that $90 \%(57 / 63)$ of the children are non-CMD when the maternal repeat size is less than 300 repeats. In contrast, when the size of the maternal allele is 300 CTG repeats or greater, $59 \%(36 / 61)$ of the children are CMD (fig 4, table 2). On the basis of our data, the estimated risk (OR) of giving birth to a CMD child is 14 times higher $(95 \%$ confidence interval $4 \cdot 7-41 \cdot 7$ ) for the mothers with a CTG repeat length of 300 or greater.

We have determined the intergenerational behaviour of the CTG repeat in the 124 mother-child pairs (table 3). An intergenerational increase of the CTG repeat was seen in 71/82 non-CMD pairs and in 40/42 CMD pairs. No change in the size of the expansion from mother to child was observed in $10 / 82$ non-CMD pairs and in 1/42 CMD pairs. An intergenerational decrease was detected in 1/82 non-CMD pairs and in 1/42 CMD pairs (table 3). The mean intergenerational amplification in the motherCMD pairs (861 repeats) is significantly greater (Student's $t$ test, $\mathrm{p}<0.001$ ) than in the group of mother-non CMD pairs (555 repeats).

\section{Discussion}

The CTG repeat size in CMD children has been determined by different authors: Tsilfidis et $a l,{ }^{12}$ Harley et $a l,{ }^{13}$ and Redman et $a l^{14}$ found some congenital cases with alleles in the 500999 repeats range and an overlap between the CMD and non-CMD patients in the 13002300 repeats range. In our series, all CMD patients had allele sizes greater than 1000 repeats and a similar overlap has been observed, suggesting that the repeat size is not the only feature determining the congenital onset of the disease.

A second parameter to be taken into account is the number of maternal repeats. We have found that the mean allele size in the mothers of CMD cases is three times higher than in mothers of non-CMD cases. This finding agrees with the data of Harley et $a l^{13}$ who found mean maternal repeat sizes of 600 and 220 for $\mathrm{CMD}$ and non-CMD children, respectively. $\mathrm{A}$ previous study ${ }^{12}$ determined that the majority of mothers of non-CMD children had allele sizes smaller than 500 repeats. Our results indicate that a cut off point of 300 repeats can be defined. This cut off point is important because of its negative predictive value: for a mother having fewer than 300 repeats, the possibility of having a CMD child is about $10 \%$. When the maternal allele is 300 repeats or greater, the possibility of predicting a CMD case is limited since only $59 \%$ of the cases are CMD. Nevertheless, at this cut off point, the estimated risk of having a CMD child for this group of mothers is 14 times greater than in mothers below 300 repeats.

Another feature involved in the risk of having a CMD child is the intergenerational behaviour of the CTG repeat. Previous studies ${ }^{12-14}$ have suggested that the repeat size invariably increases from mother to CMD children. However, we have observed an intergenerational increase of the CTG repeat in $96 \%$ of the mother-CMD pairs, a transmission without change in size in $2 \%$ of the mother-CMD pairs and a decrease in one pair. The latter showed the largest decrease of all our parent-child pairs. In this case, the mother had the typical features of DM and the largest number of repeats (2300 repeats) of our sample of $346 \mathrm{DM}$ patients. Her son has, surprisingly, inherited a smaller allele size (1300 repeats) than his mother. This case, in which CMD is inherited despite an important contraction on transmission from mother to child, should be considered in prenatal counselling. ${ }^{1819}$

Other studies have shown contradictory results about the intergenerational behaviour of CTG repeats. While, Tsilfidis et $a l^{12}$ did not identify differences in the intergenerational amplification of the mother-CMD and mothernon-CMD pairs, Redman et $\mathrm{al}^{14}$ found a clear difference between the two groups. Our results are in good agreement with the latter.

Previous studies ${ }^{16}$ have shown that multisystem disease in the mother increases the risk of having a CMD child. However, the risk always exists for an affected mother, since this study has identified the existence of CMD offspring of mothers with fewer than 100 repeats and in the presence of a dramatic intergenerational contraction.

However, the data presented in this study cannot alone explain the nearly exclusive maternal inheritance of CMD. Some authors ${ }^{1620}$ have suggested that CMD could arise from an "additive" pathology including an affected mother with metabolic disturbances and an affected developing fetus with a sufficiently high number of CTG repeats.

Finally, we can conclude that the risk of 
giving birth to a CMD child is related to the intergenerational amplification and is considerably higher if the maternal allele is greater than 300 repeats.

The authors wish to thank $\operatorname{Dr} T$ Ashizawa for his helpful comments. This work was supported by the Spanish partment of Health (FIS Projects 94/0350 and 94/1249).

1 Harper PS. Myotonic dystrophy. Philadelphia: W B Saunders, 1989

2 Aslanidis C, Jansen G, Amemiya C, et al. Cloning of the essential myotonic dystrophy region and mapping of the essential myotonic dystrophy region and

3 Brook JD, McCurrach ME, Harley HG, et al. Molecular basis of myotonic dystrophy: expansion of a trinucleotide (CTG) repeat at the $3^{\prime}$ end of a transcript encoding protein kinase family member. Cell 1992;68:799-808

4 Buxton J, Shelbourne P, Davies J, et al. Detection of an unstable fragment of DNA specific to individuals with myotonic dystrophy. Nature 1992;355:547-8.

5 Fu YH, Pizzuti A, Fenwick RG, et al. An unstable triplet repeat in a gene related to myotonic muscular dystrophy. Science 1992;255:1256-8.

6 Harley HG, Brook JD, Rundle SA, et al. Expansion of unstable DNA region and phenotypic variation in myotonic dystrophy. Nature 1992;355:545-6.

7 Mahadevan M, Tsilfidis C, Sabourin L, et al. Myotonic dystrophy mutation: an unstable CTG repeat in the $3^{\prime}$ dystrophy mutation: an unstable CTG repeat in the 3
untranslated region of the gene. Science 1992;255:1253-5.

8 Höweler CJ, Busch HFM, Geraedts GPM, Niermeijer MF Staal A. Anticipated in myotonic dystrophy: fact or fiction. Brain 1989;112:779-97.

Ashizawa T, Dunne CJ, Dubel JR, et al. Anticipation in myotonic dystrophy. I. Statistical verification based on clinical and haplotype findings. Neurology 1992;42:18717.
10 López de Munain A, Blanco A, Emparanza JI, et al. Anticipation in myotonic dystrophy: a parental sex-related phenomenon. Neuroepidemiology 1994;13:75-8.

11 Ashizawa T, Dubel JR, Dunne PW, et al. Anticipation in myotonic dystrophy. II. Complex relationships between clinical findings and structure of the GTC repeat. Neurology 1992;42:1877-83.

12 Tsilfidis C, McKenzie AE Mettler G, Barceló J, Korneluk RG. Correlation between CTG trinucleotide repeat length and frequency of severe congenital myotonic dystrophy. Nature Genet 1992;1:192-5.

13 Harley HG, Rundle SA MacMillan JC, Crow S, et al. Size of the unstable CTG repeat sequence in relation to phenotype and parental transmission in myotonic dysphenotype and parental transmission in

14 Redman JB, Fenwick R, Fu YH, Pizzuti A, Caskey T Relationship between parental trinucleotide GCT repeat length and severity of myotonic dystrophy in offspring. FAM $A$ 1993;269:1960-5.

15 Vanier TM. Dystrophia myotonica in childhood. BMF 1960; 2:1284-7.

16 Koch MC, Grimm T, Harley HG, Harper PS. Genetic risk for children of women with myotonic dystrophy. $A m f$ Hum Genet 1991;48:1084-91.

17 Griggs RC, Wood DS, and Working Group on the molecular defect in myotonic dystrophy. Criteria for establishing the validity of genetic recombination in myotonic dystrophy. validity of genetic recombing
Neurology 1989;39:420-1.

18 Cobo AM, Baiget M, López de Munain A, Poza JJ, Emparanza JI, Johnson K. Sex-related difference in inparanza JI, Johnson $K$. Sex-related difference in intergenerational expansion of

19 Ashizawa T, Anvret $M$, Baiget $M$, et al. Characteristics of intergenerational contractions of the CTG repeat in myotonic dystrophy. Am f Hum Genet 1994;54:414-23.

20 Barceló JM, Pluscauskas M, MacKenzie AE, Tsilfidis C Narang M, Korneluk RG. Additive influence of maternal and offspring DM-kinase gene CTG repeat lengths in the genesis of congenital myotonic dystrophy. Am $7 \mathrm{Hum}$ Genet 1994;54:1124-5. 